\title{
Modified Multiwalled Carbon Nanotubes for Treatment of Some Organic Dyes in Wastewater
}

\author{
M. I. Mohammed, Adnan A. Abdul Razak, and Dhiyaa A. Hussein Al-Timimi \\ Department of Chemical Engineering, University of Technology, 52 Al Sina'a Street, Baghdad, Iraq \\ Correspondence should be addressed to M. I. Mohammed; mohab1964@yahoo.com
}

Received 12 March 2014; Accepted 19 May 2014; Published 9 June 2014

Academic Editor: Manish U. Chhowalla

Copyright ( 2014 M. I. Mohammed et al. This is an open access article distributed under the Creative Commons Attribution License, which permits unrestricted use, distribution, and reproduction in any medium, provided the original work is properly cited.

\begin{abstract}
In Iraq, a large quantity of basic orange and methyl violet dyes contaminated wastewater from textile industries is discharged into Tigris River. So the aim of this work is to found an efficient and fast technique that can be applied directly for removal of such dyes from the wastewater before discharging into river. Accordingly, CNTs as a new approach prepared by CCVD technique were purified, functionalized, and used as adsorption material to remove dyes from wastewater. The effect of $\mathrm{pH}$, contact time, CNTs dosage, and dyes concentration on removal of pollutants was studied. The removal percentage of both dyes was proportional to the contact time, CNTs dosage, and $\mathrm{pH}$ and inversely proportional to the dyes concentration. The results show that the equilibrium time was 20 and $30 \mathrm{~min}$ for basic orange and methyl violet dyes, respectively, and the maximum removal percentage for all dyes concentrations was at $\mathrm{pH}=8.5$ and CNTs dosage of $0.25 \mathrm{~g} / \mathrm{L}$ and $0.3 \mathrm{~g} / \mathrm{L}$ for methyl violet and basic orange dye, respectively. The adsorption isotherm shows that the correlation coefficient of Freundlich model was higher than Langmuir model for both dyes, indicating that the Freundlich model is more appropriate to describe the adsorption characteristics of organic pollutants.
\end{abstract}

\section{Introduction}

There are more than 100,000 types of dyes commercially available, with over $7 \times 10^{5}$ tons of dyestuff produced annually, which can be classified according to their structure as anionic and cationic [1]. Dyes are ionic, aromatic organic compounds. Colored dye wastewater arises as a direct result of the production of the dye and also as a consequence of its use in the textile and other industries [2]. These dyes are very stable and can be decomposed only at temperatures higher than $200^{\circ} \mathrm{C}$. For this reason, synthetic dyes often receive considerable attention from researchers in textile wastewater treatment processes [3].

There are several techniques usually used for removal of organic dyes from wastewater. Adsorption has been found to be superior to other techniques for water reuse in terms of initial cost, flexibility and simplicity of design, ease of operation, and insensitivity to toxic pollutants $[4,5]$. CNTs, as newly emerging carbonaceous materials, have attracted considerable interests as potential adsorbents for water treatment application due to their high specific surface area, distinct structure, and modifiable surface chemistry [6]. Carbon nanotubes (CNTs) have been observed to be more efficient carbonaceous adsorbents than conventional ACs, with higher adsorption capacity [7-9], shorter equilibrium time [10, 11], and less weight loss in reactivation [8]. CNTs have been proven to possess great potential for removing many kinds of pollutants such as resorcinol [12], aniline [13], ethyl benzene [14], and phenol [15].

In Iraq, large quantity of dyes contaminated wastewater from textile industries is discharged into Tigris River. Therefore, we found it necessary to found an efficient and fast technique that can be applied directly for removal of such dyes from the wastewater before discharging into river. CNTs, as a new approach, were prepared, purified, functionalized, and used as adsorption material to remove basic orange and methyl violet dyes from wastewater under different conditions.

\section{Experimental}

2.1. Materials. CNTs were prepared by catalytic chemical vapor deposition CCVD technique schematic diagram shown 


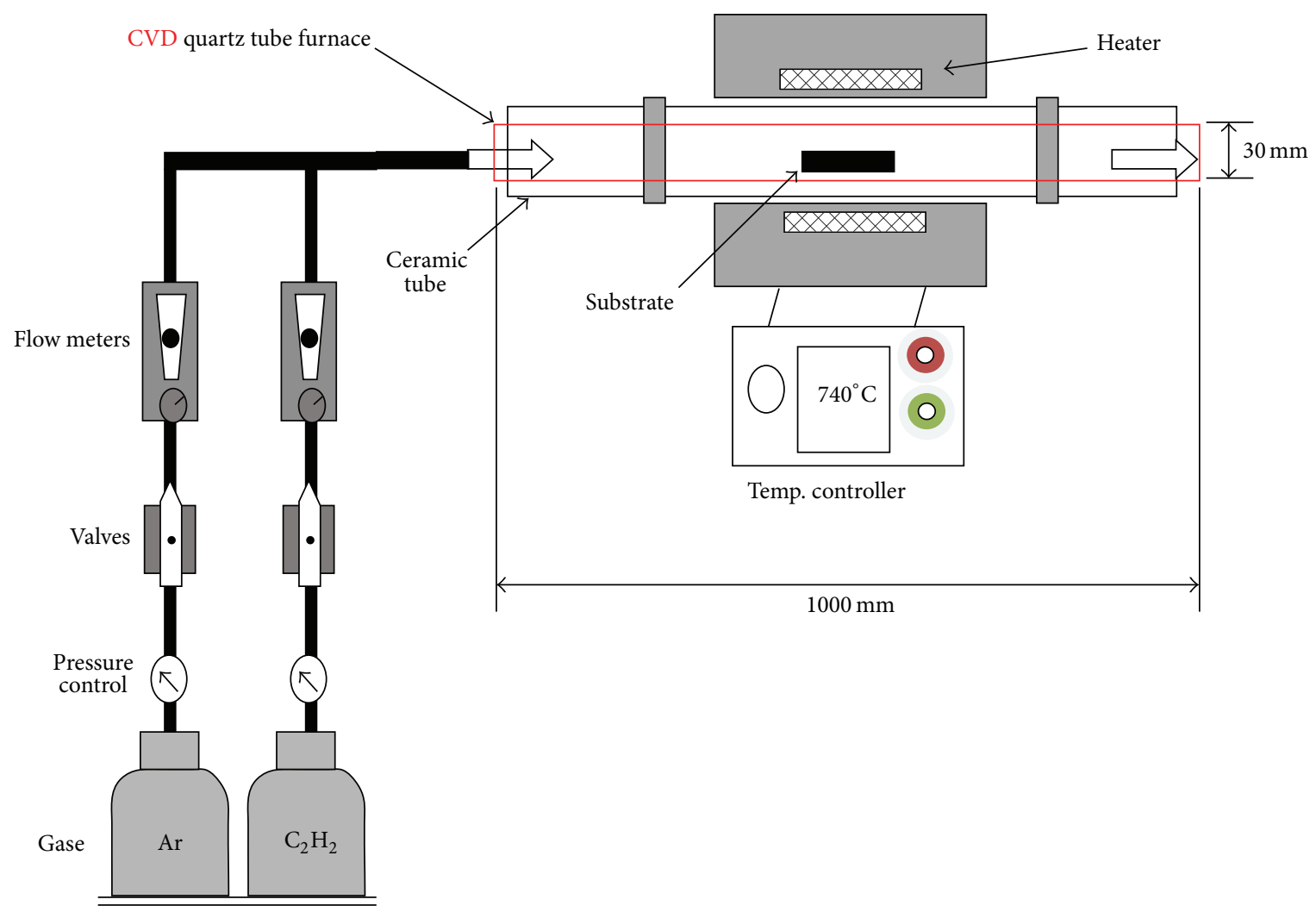

FIGURE 1: Schematic diagram of the CCVD system.

in Figure 1. CNTs were purified and functionalized in a way similar to the previously reported process [16]. After preparation of CNTs by catalytic chemical vapour deposition method, purification was used to remove the metal catalyst; 1.5 grams of CNTs was dispersed into a flask containing $100 \mathrm{~mL}$ of $6 \mathrm{M}$ hydrochloric acid and then shaken in ultrasonic cleaning bath for $60 \mathrm{~min}$. After that, it was centrifuged and rinsed with deionised water for several times until the $\mathrm{pH}$ of mixture was close to 7; the solution was filtered using millipore membrane filter $0.45 \mu \mathrm{m}$ (Chmlab group, Spain). Finally it was dried in air for 24 hours. For enhancing the dispersion and adsorption capability of CNTs, 1 gram of purified CNTs powder was mixed with $150 \mathrm{~mL}$ of $69 \%$ nitric acid under total reflux at $100^{\circ} \mathrm{C}$ for 2 hours. After CNTs solution cooled, samples were washed with deionized water several times until the $\mathrm{pH}$ reached 7 ; the solution was filtered using millipore membrane filter $0.45 \mu \mathrm{m}$. Then, CNTs dried in air for 24 hours and then dried in furnace at $140^{\circ} \mathrm{C}$ for 2 hours.

2.2. Dyes. Dyes were supplied from Al-Fateh Factory of Textile Industries, Ministry of Industry, Iraq. The characteristics of these dyes are given in Table 1.

2.3. Characterization Techniques. Different techniques such as SEM, TEM, XRD, and BET were used to identify the structure and properties of CNTs prepared.

X-Ray Diffraction device (type XRD-6000, Shimadzu) was used to determine the crystal structure of prepared CNTs.
TABLE 1: Characteristics of applied dyes used in the experiments.

\begin{tabular}{lccc}
\hline Type of dye & $\begin{array}{c}\text { Mwt. } \\
\text { gm/gmoL }\end{array}$ & $\begin{array}{c}\text { Chemical } \\
\text { structure }\end{array}$ & $\begin{array}{c}\lambda \text { max } \\
(\mathrm{nm})\end{array}$ \\
\hline $\begin{array}{l}\text { Basic orange } \\
\text { Methyl violet }\end{array}$ & 248.72 & $\mathrm{C}_{12} \mathrm{H}_{12} \mathrm{~N}_{4} \cdot \mathrm{HCl}$ & 390 \\
(6B) & 394 & $\mathrm{C}_{24} \mathrm{H}_{28} \mathrm{~N}_{3} \mathrm{Cl}$ & 580 \\
\hline
\end{tabular}

The XRD pattern of CNTs grown by the CCVD technique is shown in Figure 2. The main peaks at 2 theta $=26.1$ corresponding to the 002 plane were observed together with small peaks at 42.61 and 44.83 which are also observed and correspond to the $\{(100)$ and (101) $\}$ crystallography planes and confirm the existence of multiwall carbon nanotube within the structure [16-20].

The specific surface area of the prepared CNTs, as determined by the BET method by surface area analyzer ( $Q$ Surf 1600 , USA), was found to be $166 \mathrm{~m}^{2} / \mathrm{g}$. The analyzed structure and quality of the prepared CNTs were identified by scanning electron microscopy (SEM) (type TESCAN); Figure 3(a) shows SEM image of CNTs grown. The range of main external diameters of CNTs was 50-85 nm.

The internal structure of sample of carbon nanotubes prepared was identified by transmission electron microscope (TEM). Figure 3(b) displays the morphology of CNTs prepared. The TEM figure shows that the CNTs are cylindrical and that the range of external diameters is $20-80 \mathrm{~nm}$. The TEM analysis confirms the growth of MWCNTs structure, 


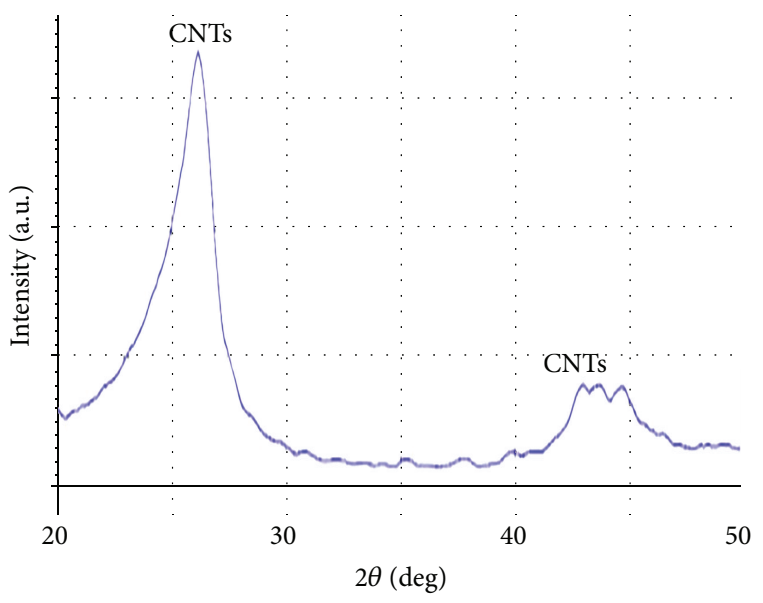

Figure 2: X-ray diffraction of CNTs produced.

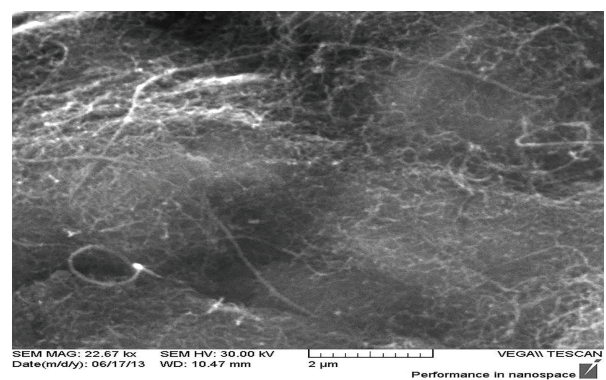

(a)

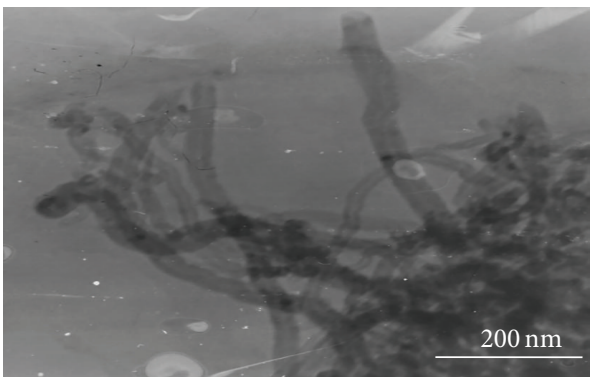

(b)

FIGURE 3: (a) SEM image of the prepared CNTs. (b) TEM image of the prepared CNTs.

and most of the carbon nanotubes have closed tips and catalyst particles are encapsulated at the tip or somewhere inside the tube.

The FTIR spectra were observed by FTIR spectrometer model (Shimadzu 8400 S, Japan). FTIR for both as-prepared and functionalized MWCNTs is shown in Figure 4. No carbonyl groups have been detected within this structure. Characteristic bands due to generated polar functional groups are observed for CNTs oxidized in $\mathrm{HNO}_{3}$. The band at $1741.78 \mathrm{~cm}^{-1}$ can be assigned to the stretching variations of $\mathrm{C}=\mathrm{O}$ groups [21], the peak at $3742.03 \mathrm{~cm}^{-1}$ is attributed to free hydroxyl groups, and the peak at $3439.19 \mathrm{~cm}^{-1}$ can be

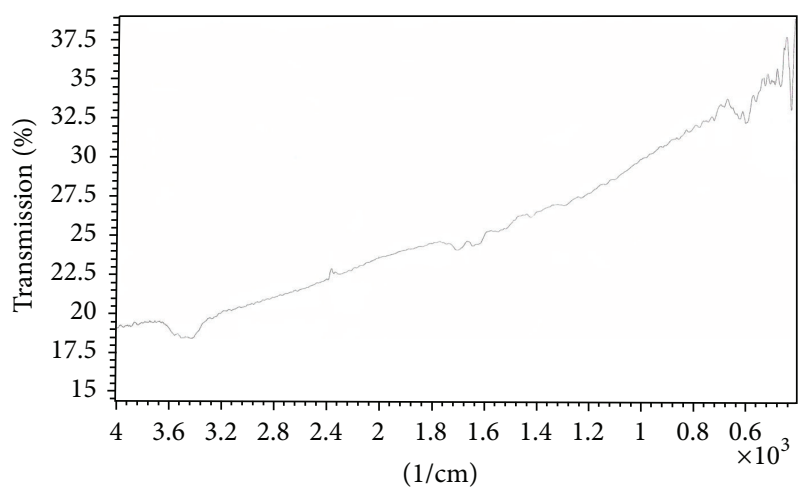

(a)

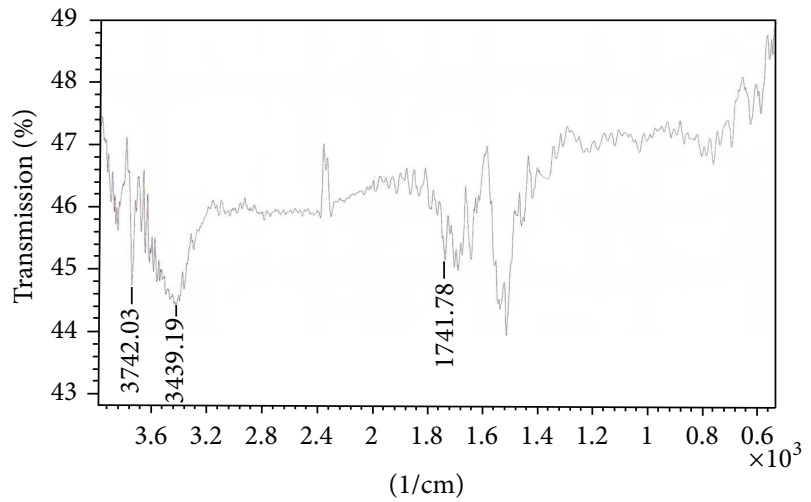

(b)

FIGURE 4: (a) FTIR of as-produced CNTs. (b) FTIR of functionalized CNTs.

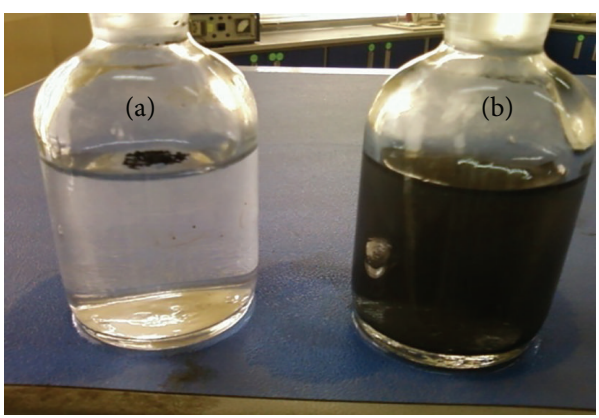

FIGURE 5: Dispersibility behavior of (a) as-prepared and (b) modified CNTs.

assigned to the $\mathrm{O}-\mathrm{H}$ stretch from carboxyl groups $(\mathrm{O}=\mathrm{C}-\mathrm{OH}$ and $\mathrm{C}-\mathrm{OH})[22]$.

Nanotubes due to their carbonic nature and also presence of van der Waals attraction between tubes are hydrophobic, so they exhibit low dispensability in water and organic solvents and irradiating them with ultrasonication does not improve their dispersibility as shown in Figure 5(a). However, chemically treated CNTs show hydrophilic behaviors and the acid washed CNTs. Figure 5(b) shows better dispersibility and form of $\mathrm{OH}$-group [23]. 


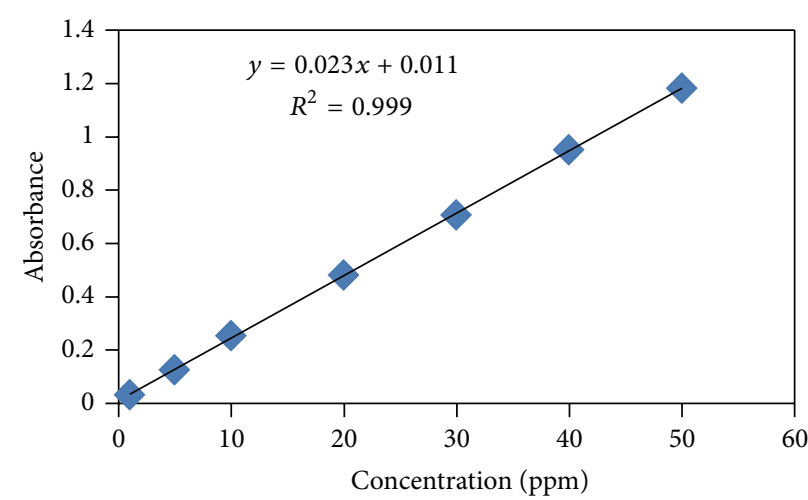

(a)

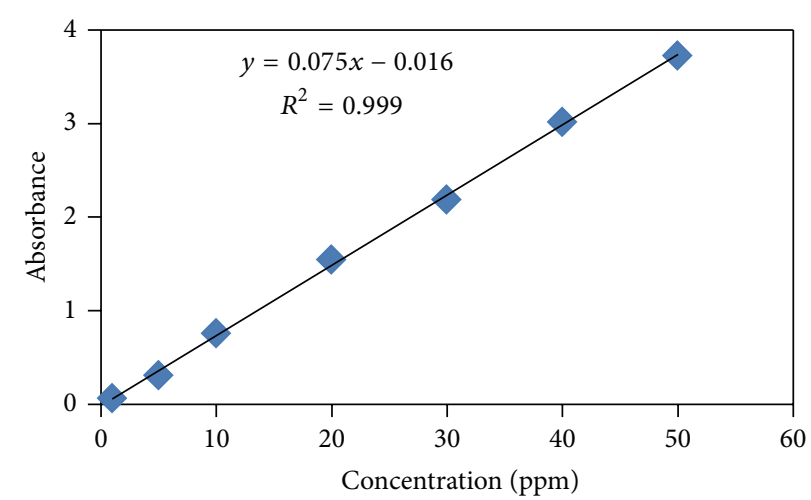

(b)

Figure 6: (a) Calibration curve of basic orange dye. (b) Calibration curve of methyl violet dye.

2.4. Batch Adsorption Experiment. The maximum wavelength $(\lambda \max )$ for basic orange and methyl violet was measured at $390 \mathrm{~nm}$ and $580 \mathrm{~nm}$, respectively, and was used to determine the absorbencies using UV-Spectrometer model (1100 Chrom Tech/China).

Analysis of samples was carried out based on standard methods and the calibration curves of basic orange and methyl violet dyes are shown in Figures 6(a) and 6(b), respectively. The stock solution of dyes was prepared by diluting $1 \mathrm{~g}$ of the dye powder in $1000 \mathrm{~mL}$ deionized water in an appropriate volumetric flask. The stock solution was then diluted to the desired initial concentrations of 5, 10, 20 , and $30 \mathrm{mg} / \mathrm{L}$. An amount of 100,200 , and $300 \mathrm{mg} / \mathrm{L}$ for basic orange dye and 50, 150, and $250 \mathrm{mg} / \mathrm{L}$ for methyl violet dye adsorbent (CNTs) was added to $100 \mathrm{~mL}$ conical flasks filled with $50 \mathrm{~mL}$ of dye solutions of known initial concentrations. The conical flasks were placed inside the shaker and shaking speed was $250 \mathrm{rpm}$ at room temperature $25 \pm 2^{\circ} \mathrm{C}$ and samples were taken at predetermined time intervals. Dye concentrations after sorption were analyzed using a UV-Spectrometer. The effects of various variables affecting the adsorption of dyes over CNTs were determined during batch experiments. The $\mathrm{pH}$ of each solution was adjusted using $0.1 \mathrm{M} \mathrm{HCl}$ or $0.1 \mathrm{M} \mathrm{NaOH}$. The $\mathrm{pH}$ of solutions was measured with a $\mathrm{pH}$ meter (Hanna 211, Romania).

The amount of dyes adsorbed onto CNT, $q(\mathrm{mg} / \mathrm{g})$, was calculated by the mass balance relationship:

$$
q=\frac{C_{0}-C_{f}}{m} V
$$

where $q$ is adsorption capacity $(\mathrm{mg} / \mathrm{g}), m(\mathrm{~g})$ is the mass of adsorbent CNTs, $V$ (L) is the volume of dye solution, and $C_{0}$ and $C_{f}(\mathrm{mg} / \mathrm{L})$ are the dye solution concentration initially and finally, respectively. The adsorption percentage (removal efficiency), $\mathrm{Re} \%$, of each dye was calculated as follows:

$$
\operatorname{Re} \%=\frac{C_{0}-C_{f}}{C_{0}} \times 100
$$

\section{Results and Discussion}

\subsection{Variables Affect Adsorption Dyes by Functionalized MWCNTs}

3.1.1. Effect of Contact Time. The effect of contact time on the adsorption \% of basic orange dye is shown in Figure 7(a), and the effect of contact time on adsorption capacity of basic orange dye is shown in Figure 7(b). It is clearly obvious that the time of 20 minutes is sufficient for dye adsorption to reach equilibrium. The effect of contact time on the adsorption \% of methyl violet dye is shown in Figure 8(a) and the effect of contact time on adsorption capacity of methyl violet dye is shown in Figure 8(b). In such cases, time of 30 minutes is sufficient to reach equilibrium state of methyl violet dye adsorption. The results also show that the adsorption is very fast initially and then slowly reaches the adsorption equilibrium. This can be the consequence of the fact that a large number of free surface sites are available for sorption during the initial stage and, afterwards, the remaining free surface sites are difficult to be occupied, because of repulsive forces between the phases [24]. It indicates that the adsorption mechanism of CNTs is completely different from that of activated carbon. The adsorption by activated carbon depends mainly on the porous structure, so it takes time for adsorbents to diffuse through pores [10], while the spaces available for adsorption in CNTs are mainly due to the surface site of external wall of cylindrical shape and do not depend on the inner cavities and inner wall spacing [25].

3.1.2. Effect of $p H$. The $\mathrm{pH}$ of the aqueous solution is an important factor to affect the dye adsorption process through changing the surface charge of an adsorbent and the ionization behavior of adsorbent and dye.

The influences of the solution $\mathrm{pH}$ on basic orange and methyl violet dyes removal \% by CNTs are shown in Figures $9(\mathrm{a})$ and $9(\mathrm{~b})$, respectively.

It can be seen that the basic orange and methyl violet dyes removal efficiencies increase with increasing $\mathrm{pH}$ in $\mathrm{pH}$ range of 3.0-8.5. The maximum removal was achieved at $\mathrm{pH} 8.5$ and no increasing adsorption at $\mathrm{pH}$ beyond 8.5 . This may be 


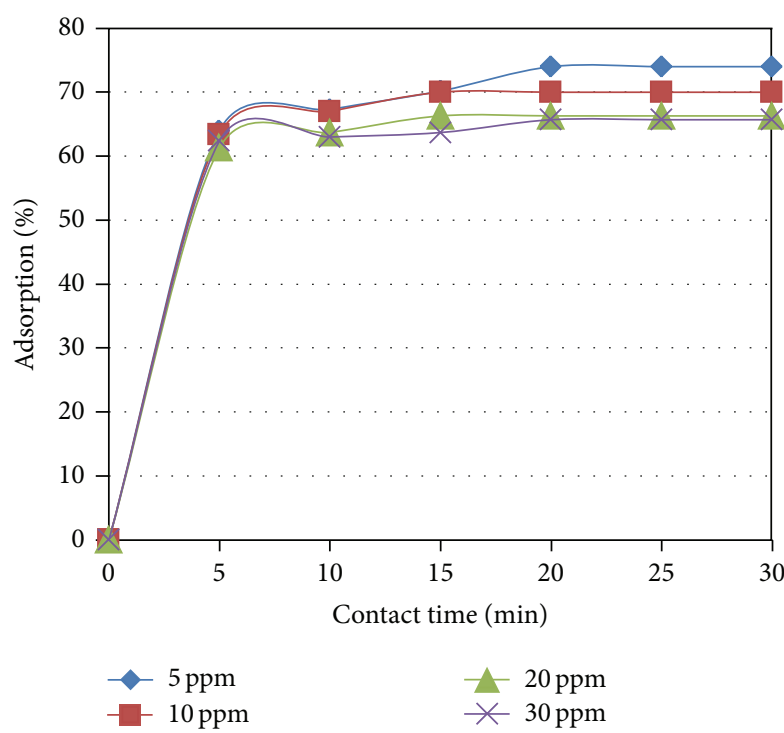

(a)

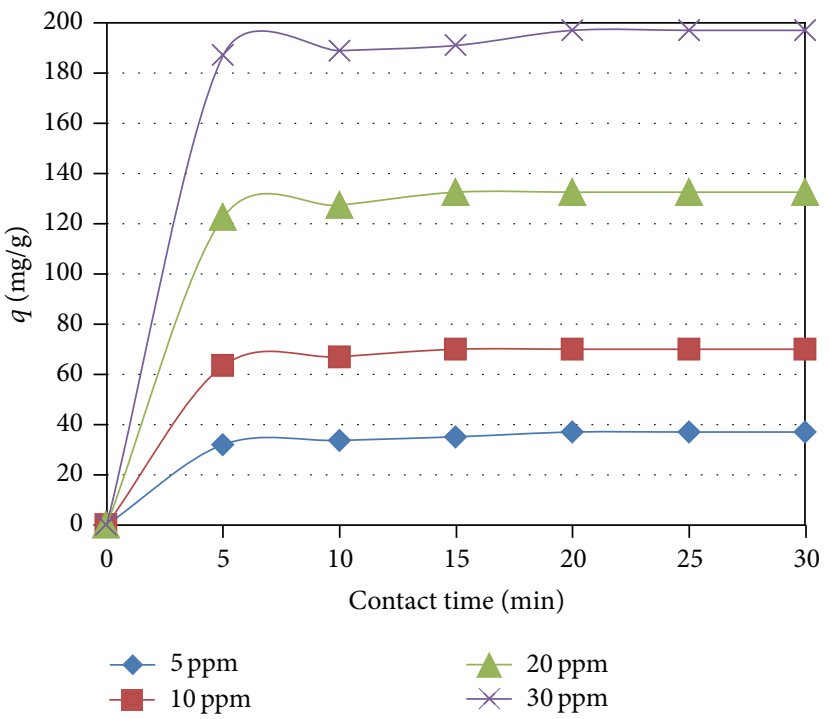

(b)

FIGURE 7: (a) Effect of contact time on basic orange dye adsorbed $\%(\mathrm{pH}=8.5$, CNTs dosage $=100 \mathrm{mg} / \mathrm{L})$. (b) Effect of contact time on basic orange dye adsorption capacity $(\mathrm{pH}=8.5$, CNTs dosage $=100 \mathrm{mg} / \mathrm{L})$.

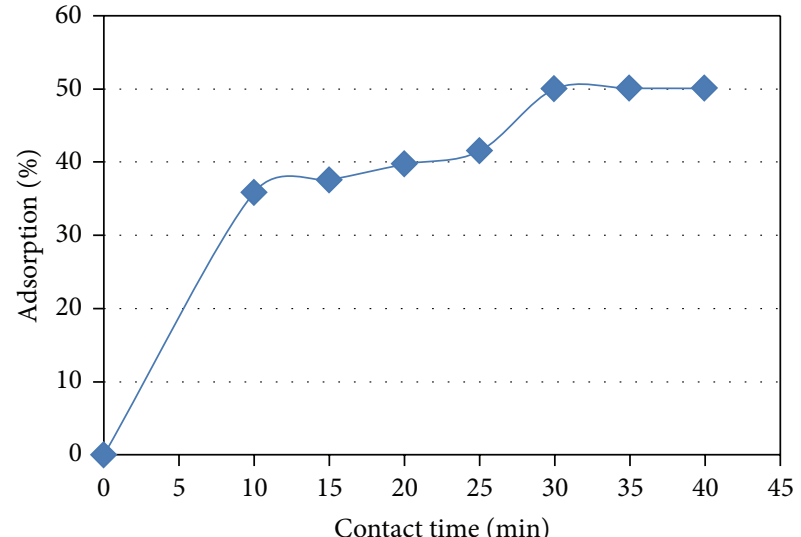

$30 \mathrm{ppm}$

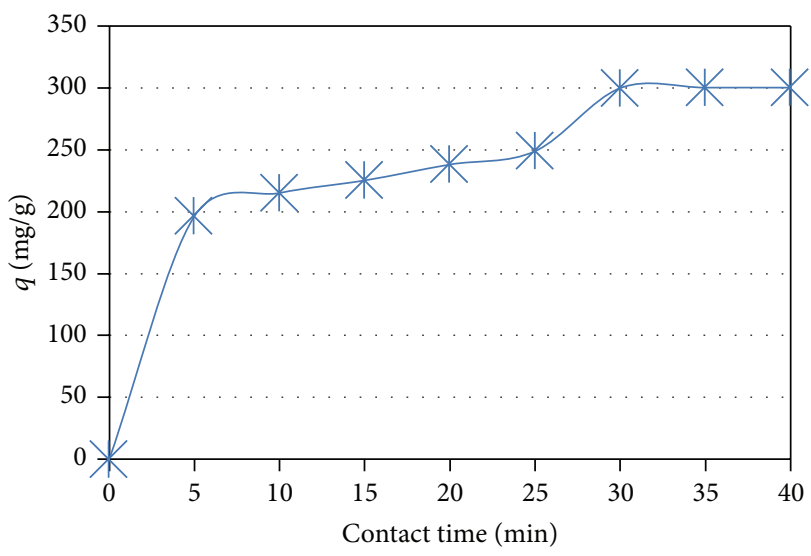

(b)

FIGURE 8: (a) Effect of contact time on methyl violet dye adsorption $\%(\mathrm{pH}=8.5$, CNTs dosage $=50 \mathrm{mg} / \mathrm{L})$. (b) Effect of contact time on methyl violet dye adsorption capacity $(\mathrm{pH}=8.5$, CNTs dosage $=50 \mathrm{mg} / \mathrm{L})$.

due to the modified CNTs surfaces which introduce anionic group $\left(\mathrm{COO}^{-}\right)$and thus improve their ion exchange property for selective adsorption of oppositely charged species (dyes) from aqueous solutions through electrostatic force of interactions.

The mechanism for dye removal may be explained as follows: at low $\mathrm{pH}$ values the excessive hydrogen ions in the solution may compete with the dyes cations for the active sites $\left(\mathrm{COO}^{-}\right)$of functionalized CNTs and hence a lower adsorption $\%$ and adsorption capacity of dyes are observed compared with higher $\mathrm{pH}$ value.

At higher $\mathrm{pH}$ values, the cations dyes are easily attached on the surface of negatively charged functionalized CNTs through electrostatic force attractions [26]. The removal \% of basic orange dye increases from $55,47,37.7$, and 32.6 to 74 , $70,66.3$, and 65.7 for dye concentration $5,10,20$, and $30 \mathrm{ppm}$, respectively, with the increase in $\mathrm{pH}$ from 3 to 8.5 , while the removal \% of methyl violet dye increases from 16.83 to 50 for dye concentration of $30 \mathrm{ppm}$ with the increase in $\mathrm{pH}$ from 3 to 8.5 .

3.1.3. Effect of Modified CNTs Dosage. The effects of CNTs dosage on the adsorption process of basic orange dye are shown in Figure 10(a) and for methyl violet dye are shown in Figure 10(b).

In order to find the optimum dosage of CNTs, three doses of adsorbent were investigated $0.1,0.2$, and $0.3 \mathrm{~g} / \mathrm{L}$ with basic orange dye and $0.05,0.15$, and $0.25 \mathrm{~g} / \mathrm{L}$ with methyl violet dye. 


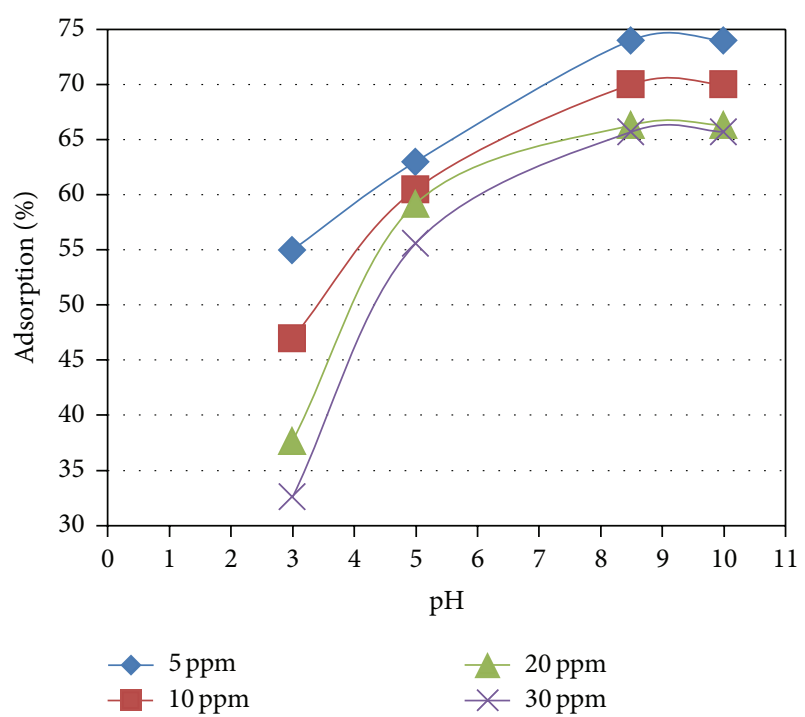

(a)

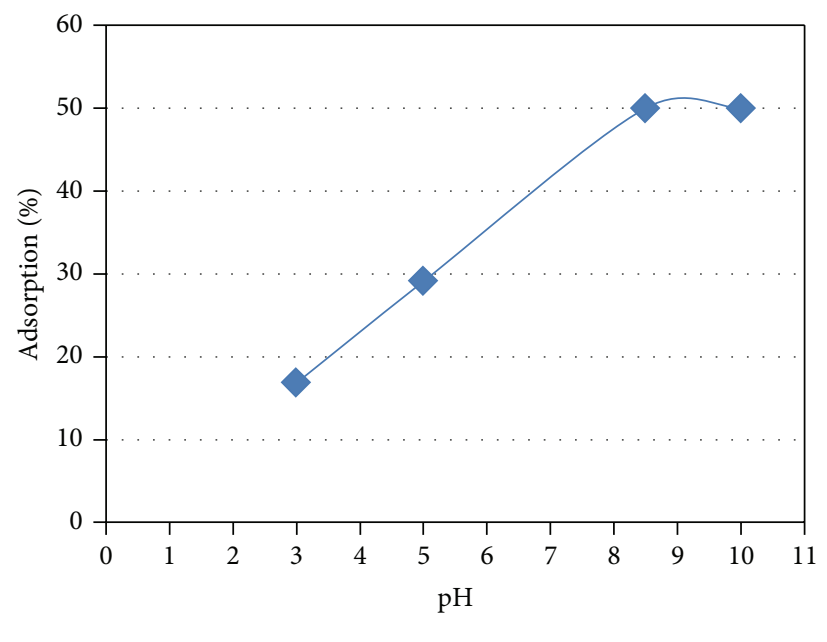

$30 \mathrm{ppm}$

(b)

Figure 9: (a) Effect of $\mathrm{pH}$ on basic orange dye adsorbed \% (contact time $=30 \mathrm{~min}$, CNTs dosage $=100 \mathrm{mg} / \mathrm{L}$ ). (b) Effect of pH on methyl violet dye adsorbed $\%$ (contact time $=40 \mathrm{~min}, \mathrm{CNTs}$ dosage $=50 \mathrm{mg} / \mathrm{L}$ ).

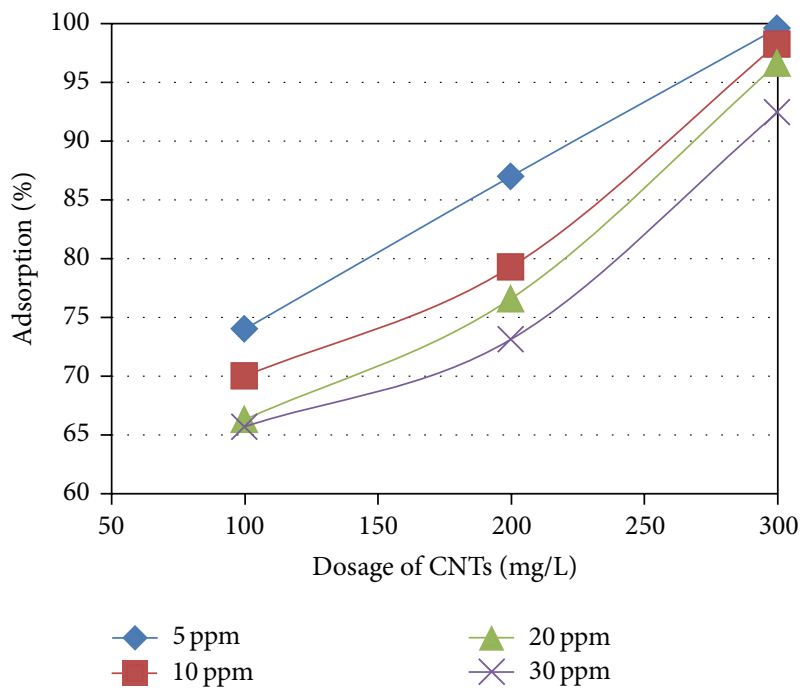

(a)

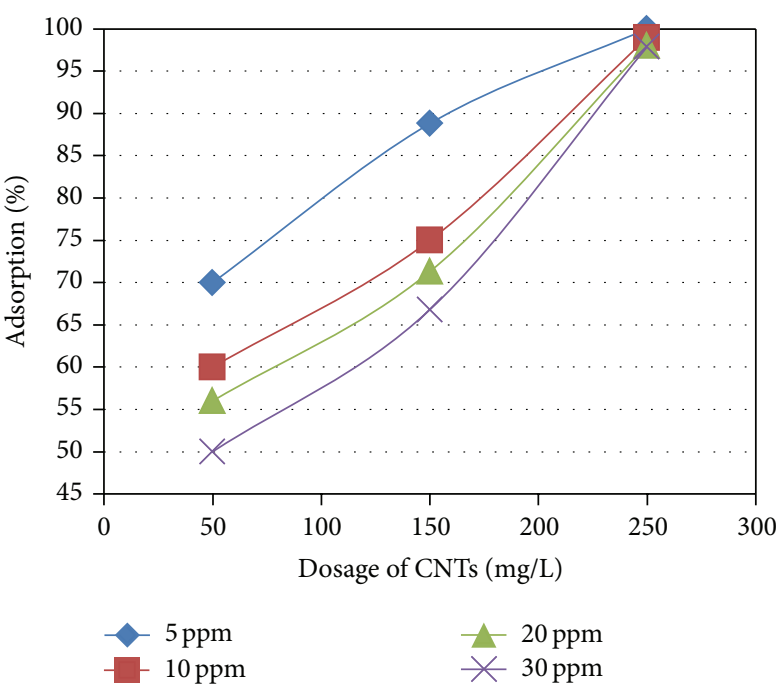

(b)

Figure 10: (a) Effect of CNTs dosage on basic orange dye adsorbed \% (contact time $=30 \mathrm{~min}, \mathrm{pH}=8.5$ ). (b) Effect of CNTs dosage on methyl violet dye adsorbed $\%$ (contact time $=40 \mathrm{~min}, \mathrm{pH}=8.5$ ).

The tests were performed at contact time of $30 \mathrm{~min}$ for basic orange dye and $40 \mathrm{~min}$ for methyl violet dye and $\mathrm{pH}$ 8.5.

For the results shown in Figure 10(a) for basic orange dye concentrations of $5,10,20$, and $30 \mathrm{mg} / \mathrm{L}$, the adsorption $\%$ was 74, 70, 66.3, and 65.7, respectively, for CNTs dosage of $0.1 \mathrm{~g} / \mathrm{L}$; when the CNTs dosage increased to $0.3 \mathrm{~g} / \mathrm{L}$ the adsorption $\%$ increased to $99.6,98.26,96.6$, and 92.43 . For the results shown in Figure 10(b) for methyl violet dye concentrations of $5,10,20$, and $30 \mathrm{mg} / \mathrm{L}$, the adsorption $\%$ was $70,60,56$, and 50 , respectively, for CNTs dosage of $0.05 \mathrm{~g} / \mathrm{L}$; when the CNTs dosage increased to $0.25 \mathrm{~g} / \mathrm{L}$ the adsorption \% increased to 99.95, 98.935, 98.04, and 97.87. An increase in adsorption rate with adsorbent dosage can be attributed to increased surface area and the availability of more adsorption sites [27].

3.1.4. Effect of Initial Dye Concentration. From the results obtained in Figures 11(a) and 11(b) the percentage removal of basic orange and methyl violet dyes increases with decreasing initial dye concentration, where the highest percentage removal is achieved in $5 \mathrm{mg} / \mathrm{L}$ for both dyes.

Removal of basic orange and methyl violet dyes from CNTs is dependent on initial dye concentration; at an initial concentration of $30 \mathrm{mg} / \mathrm{L}$ of basic orange dye the maximum removal percentage was found to be $92.43 \%$ and, by decreasing the basic orange dye concentration to $5 \mathrm{mg} / \mathrm{L}$, the removal 


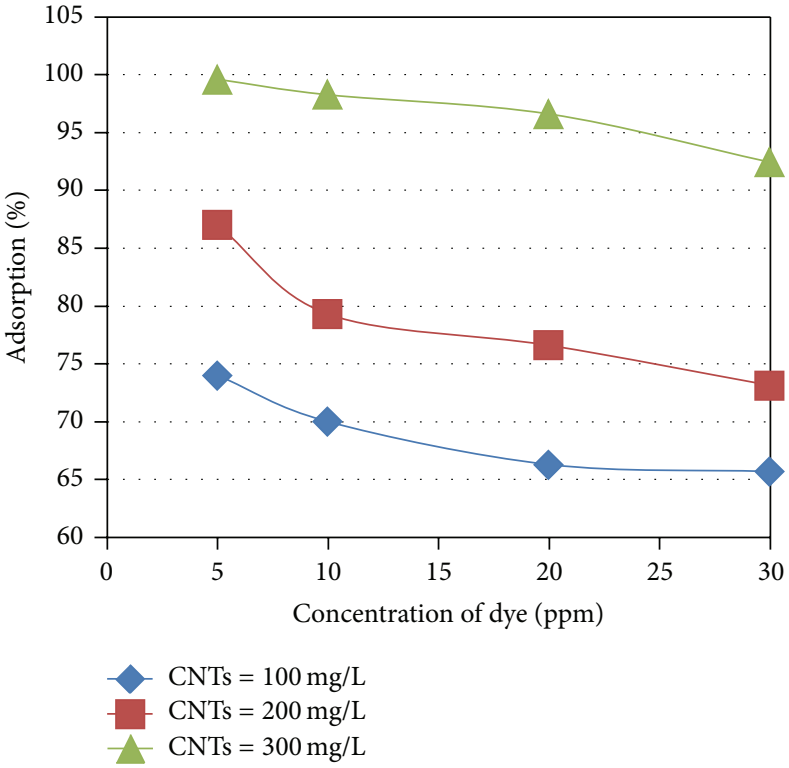

(a)

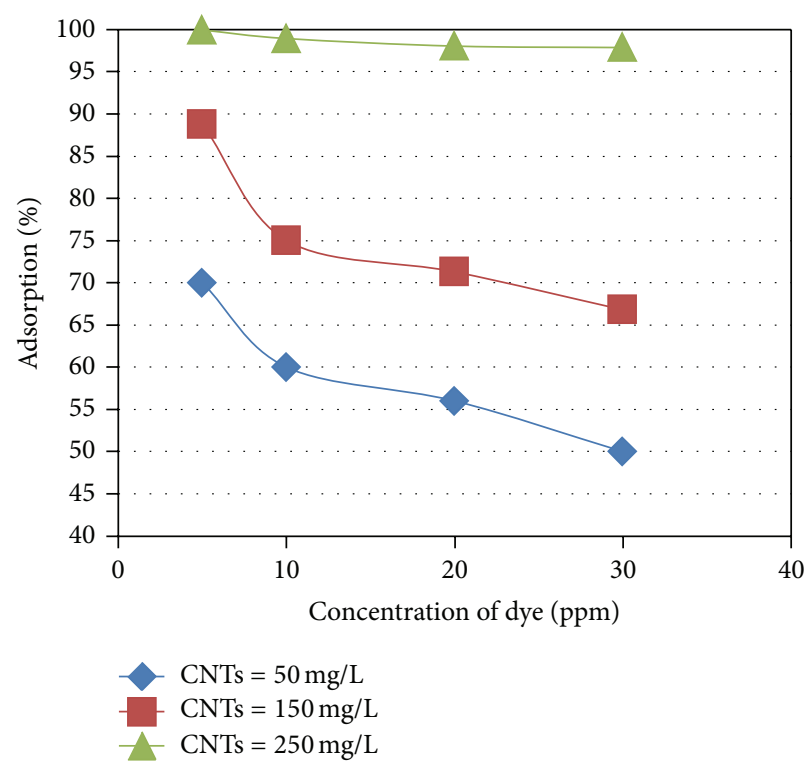

(b)

Figure 11: (a) Effect of basic orange dye initial concentration on adsorbed $\%$ (contact time $=30 \mathrm{~min}, \mathrm{pH}=8.5$ ). (b) Effect of methyl violet dye initial concentration on adsorbed $\%$ (contact time $=40 \mathrm{~min}, \mathrm{pH}=8.5$ ).

percentage increases to $99.6 \%$ and, at an initial concentration of $30 \mathrm{mg} / \mathrm{L}$ of methyl violet dye, the maximum removal percentage was found to be $97.87 \%$ and, by decreasing the methyl violet dye to $5 \mathrm{mg} / \mathrm{L}$, the removal percentage increased to $99.95 \%$. For constant dosage of CNTs adsorbent at lower initial dyes concentration the large number of vacant surface sites was available for adsorption of dyes. Meanwhile, by increasing dyes concentration, adsorption sites of adsorbent became lower and due to repulsive forces between dyes molecules on CNTs, the occupation of remaining vacant surface sites was difficult [1].

3.1.5. Adsorption Isotherms. Adsorption isotherms provide qualitative information on the capacity of the adsorbent as well as the nature of the solute-surface interaction. In this study, two isotherm models, Langmuir and Freundlich models, were studied to describe the equilibrium characteristics of adsorption [1]. The adsorption isotherm models of Freundlich (see (3)) and Langmuir (see (4)) can be represented by the following linear forms:

$$
\begin{aligned}
\log q & =\log K_{F}+\frac{1}{n} \log C_{e}, \\
\frac{C_{e}}{q} & =\frac{1}{\left(K_{L} q_{m}\right)}+\frac{C_{e}}{q_{m}},
\end{aligned}
$$

where $q$ is the equilibrium of adsorbate concentration on adsorbent $(\mathrm{mg} / \mathrm{g}), C_{e}$ is the equilibrium concentration of adsorbate in solution $(\mathrm{mg} / \mathrm{L}), K_{F}$ and $n$ are the Freundlich constants, which represent the adsorption capacity and the adsorption strength, respectively, $K_{L}$ is the Langmuir constant $(\mathrm{L} / \mathrm{mg})$, and $q_{m}$ is the theoretical saturation capacity of the monolayer $(\mathrm{mg} / \mathrm{g})$. The plot of $\log C_{e}$ versus $\log q$ in
TABLE 2: Adsorption isotherm constants of Freundlich model for basic orange dye $(\mathrm{pH}=8.5$ and contact time $=30 \mathrm{~min})$.

\begin{tabular}{lccc}
\hline $\begin{array}{l}\text { CNTs dosage } \\
(\mathrm{mg} / \mathrm{L})\end{array}$ & $\begin{array}{c}K_{F} \\
\mathrm{mg} / \mathrm{g} \\
(\mathrm{L} / \mathrm{mg})^{1 / n}\end{array}$ & $n$ & $R^{2}$ \\
\hline 100 & 29.4985 & 1.2466 & 0.9987 \\
200 & 27.3716 & 1.5352 & 0.9905 \\
300 & 69 & 2.6738 & 0.9913 \\
\hline
\end{tabular}

TABle 3: Adsorption isotherm constants of Freundlich model for methyl violet dye $(\mathrm{pH}=8.5$ and contact time $=40 \mathrm{~min})$.

\begin{tabular}{lccc}
\hline $\begin{array}{l}\text { CNTs dosage } \\
(\mathrm{mg} / \mathrm{L})\end{array}$ & $\begin{array}{c}K_{F} \\
\mathrm{mg} / \mathrm{g} \\
(\mathrm{L} / \mathrm{mg})^{1 / n}\end{array}$ & $n$ & $R^{2}$ \\
\hline 50 & 52.3480 & 1.5451 & 0.9940 \\
150 & 36.9913 & 1.9 & 0.9662 \\
250 & 105.78 & 3.3795 & 0.9063 \\
\hline
\end{tabular}

Figure 12(a) for basic orange dye and Figure 12(b) for methyl violet dye is employed to evaluate the intercept $K_{F}$ and the slope $1 / n$. The values of $K_{F}$ and $n$ and the linear correlation $\left(R^{2}\right)$ of Freundlich isotherm are given in Table 2 for basic orange dye and Table 3 for methyl violet dye. Figures 13(a) and 13(b) for basic orange and methyl violet dyes, respectively, illustrate Langmuir isotherm plot for experimental data $\left(C_{e}\right.$ versus $\left.C_{e} / q\right)$. The values of $q_{m}$, intercept $K_{L}$, and the linear correlation $\left(R^{2}\right)$ of Langmuir isotherm are given in Table 4 for basic orange dye and Table 5 for methyl violet dye.

It is found that the Freundlich isotherm with $R^{2}=$ $(0.9987,0.9905$, and 0.9913$)$ and $(0.9940,0.9662$, and 0.9063$)$ 


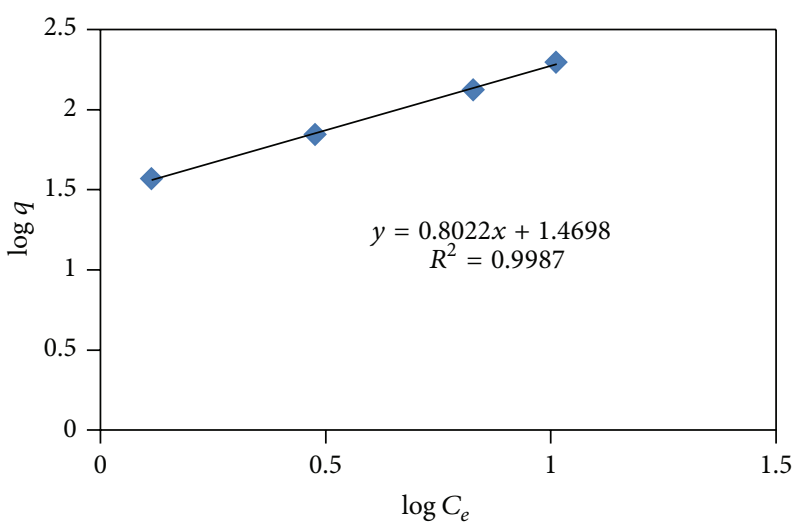

(a)

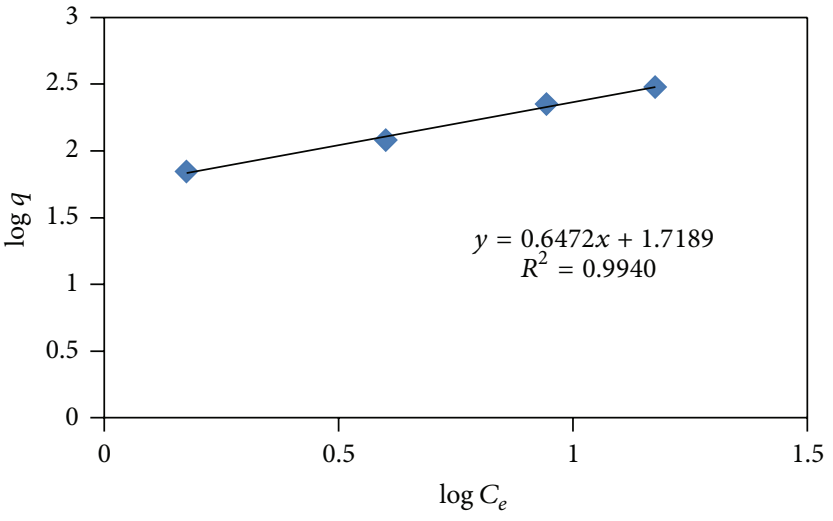

(b)

Figure 12: (a) Freundlich isotherm of basic orange dye adsorption onto CNTs $(\mathrm{pH}=8.5, \mathrm{CNTs}=100 \mathrm{mg} / \mathrm{L}$, contact time $=30 \mathrm{~min}) .(\mathrm{b})$ Freundlich isotherm of methyl violet dye adsorption onto CNTs $(\mathrm{pH}=8.5, \mathrm{CNTs}=50 \mathrm{mg} / \mathrm{L}$, contact time $=40 \mathrm{~min}$ ).

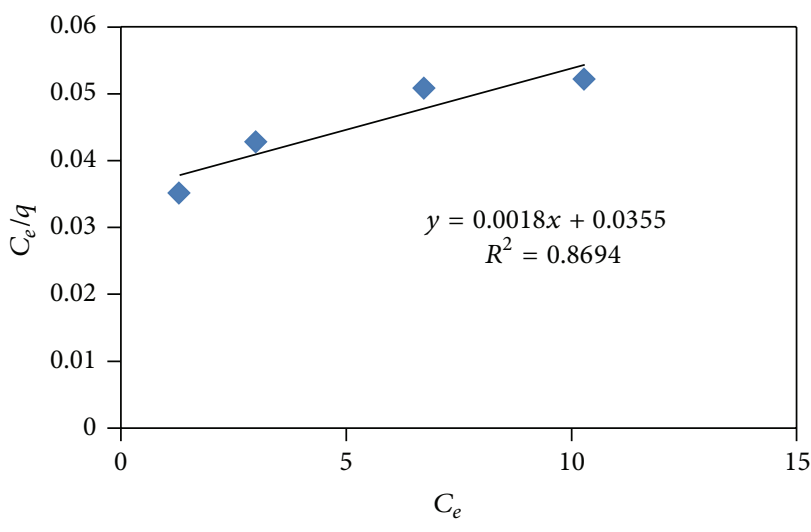

(a)

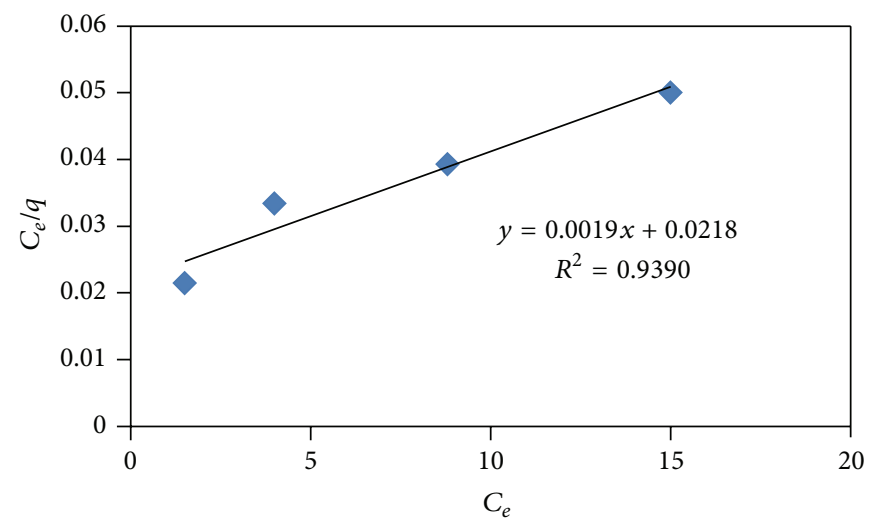

(b)

Figure 13: (a) Langmuir isotherm of basic orange dye adsorption onto CNTs $(\mathrm{pH}=8.5, \mathrm{CNTs}=100 \mathrm{mg} / \mathrm{L}$, contact time $=30 \mathrm{~min})$. $(\mathrm{b})$ Langmuir isotherm of methyl violet dye adsorption onto $\mathrm{CNTs}(\mathrm{pH}=8.5, \mathrm{CNTs}=50 \mathrm{mg} / \mathrm{L}$, contact time $=40 \mathrm{~min})$.

TABLE 4: Adsorption isotherm constants of Langmuir model for basic orange dye $(\mathrm{pH}=8.5$ and contact time $=30 \mathrm{~min})$.

\begin{tabular}{lccc}
\hline $\begin{array}{l}\text { CNTs dosage } \\
(\mathrm{mg} / \mathrm{L})\end{array}$ & $\begin{array}{c}q_{\mathrm{m}} \\
\mathrm{mg} / \mathrm{g}\end{array}$ & $\begin{array}{c}K_{L} \\
\mathrm{~L} / \mathrm{mg}\end{array}$ & $R^{2}$ \\
\hline 100 & 555.55 & 0.0507 & 0.8694 \\
200 & 188.68 & 0.1573 & 0.8767 \\
300 & 102.04 & 3.6296 & 0.9830 \\
\hline
\end{tabular}

represents the best fit with the adsorption experimental data; the high correlation coefficient obtained indicates high affinity between adsorbent surface of CNTs and basic orange and methyl violet dyes which plays the major role in the adsorption mechanism. This might be because the adsorbent surface is nonhomogeneous and there could be more than one type of sorption sites on the surface [28].

The magnitude of the $n$ gives an indication of the favorability of adsorption. Values of $n>1$ in the range of 1-10 (in this study 1.2466, 1.5352, and 2.6738 for basic orange dye
TABLE 5: Adsorption isotherm constants of Langmuir model for methyl violet dye $(\mathrm{pH}=8.5$ and contact time $=40 \mathrm{~min})$.

\begin{tabular}{lccc}
\hline $\begin{array}{l}\text { CNTs dosage } \\
(\mathrm{mg} / \mathrm{L})\end{array}$ & $\begin{array}{c}q_{\mathrm{m}} \\
\mathrm{mg} / \mathrm{g}\end{array}$ & $\begin{array}{c}K_{L} \\
\mathrm{~L} / \mathrm{mg}\end{array}$ & $R^{2}$ \\
\hline 50 & 526.31 & 0.0871 & 0.9390 \\
150 & 188.68 & 0.203 & 0.8505 \\
250 & 128.2 & 7.09 & 0.8501 \\
\hline
\end{tabular}

and $1.5451,1.90$, and 3.3795 for methyl violet dye) represent favorable adsorption condition $[29,30]$.

\section{Conclusions}

The MWCNTs prepared, purified, and functionalized in this study are successfully used in complete removals of dyes from wastewater. Such process may be considered as a promising method for removal of pigments, dyes, and other organic species from wastewater, particularly applying for wastewater store in a tank of textile factories which can be treated by 
our process before discharge into river. Purified and functionalized CNTs identified by FTIR clearly show the presence of functional groups. Such groups offer free active sites anionic groups and thus improve their ion exchange property for selective adsorption of oppositely charged species (basic orange and methyl violet dyes). Modified CNTs show better dispersibility in water. The carbon nanotubes which were prepared in this study are found to be efficient for the adsorption of organic pollutants (basic orange and methyl violet dyes). The removal percentage of organic dyes increases with increase in the contact time, CNTs dosage, and $\mathrm{pH}$ and decreases with increase in dyes concentrations. The adsorption isotherms of both dyes have been well fitted by Freundlich model compared with Langmuir model. CNTs as adsorbent have many advantages compared with activated carbon. CNTs can act as more effective adsorbent than activated carbon in terms of larger adsorption capacity, shorter equilibrium time, superior adsorption selectivity, and easier regeneration.

\section{Conflict of Interests}

The authors declare that there is no conflict of interests regarding the publication of this paper.

\section{Acknowledgment}

The authors are thankful to the Chemical Engineering Department, University of Technology, for their support and providing space and facilities.

\section{References}

[1] M. Shirmardi, A. Mesdaghinia, A. H. Mahvi, S. Nasseri, and R. Nabizadeh, "Kinetics and equilibrium studies on adsorption of acid red 18 (Azo-Dye) using multiwall carbon nanotubes (MWCNTs) from aqueous solution," E-Journal of Chemistry, vol. 9, no. 4, pp. 2371-2383, 2012.

[2] S. J. Allen and B. Koumanova, "Decolorisation of water/wastewater using adsorption," Journal of the University of Chemical Technology and Metallurgy, vol. 40, no. 3, pp. 175-192, 2005.

[3] E. R. Trotman, Dyeing and Chemical Technology of Textile Fibres, New York, NY, USA, 6th edition, 1984.

[4] Y. M. Slokar and L. M. A. Marechal, "Methods of decoloration of textile wastewaters," Dyes and Pigments, vol. 37, pp. 335-356, 1998.

[5] H. Qiu, L. Lv, B.-C. Pan, Q.-J. Zhang, W.-M. Zhang, and Q.-X. Zhang, "Critical review in adsorption kinetic models," Journal of Zhejiang University: Science A, vol. 10, no. 5, pp. 716-724, 2009.

[6] S. Ting, Z. Shujuan, and K. Tanju, "Adsorption of Organic Chemicalson Carbon Nanotubes In Aquatic Environment," Department of Environmental Engineering and Earth Sciences, Clemson University, 2010.

[7] K. Yang and B. Xing, "Adsorption of fulvic acid by carbon nanotubes from water," Environmental Pollution, vol. 157, no. 4, pp. 1095-1100, 2009.

[8] F. Su and C. Lu, "Adsorption kinetics, thermodynamics and desorption of natural dissolved organic matter by multiwalled carbon nanotubes," Journal of Environmental Science and Health A, vol. 42, no. 11, pp. 1543-1552, 2007.
[9] L. Ji, W. Chen, L. Duan, and D. Zhu, "Mechanisms for strong adsorption of tetracycline to carbon nanotubes: a comparative study using activated carbon and graphite as adsorbents," Environmental Science \& Technology, vol. 43, p. 7, 2009.

[10] X. Peng, Y. Li, Z. Luan et al., "Adsorption of 1,2-dichlorobenzene from water to carbon nanotubes," Chemical Physics Letters, vol. 376, no. 1-2, pp. 154-158, 2003.

[11] C. Lu, Y.-L. Chung, and K.-F. Chang, "Adsorption of trihalomethanes from water with carbon nanotubes," Water Research, vol. 39, no. 6, pp. 1183-1189, 2005.

[12] Q. Liao, J. Sun, and L. Gao, "The adsorption of resorcinol from water using multi-walled carbon nanotubes," Colloids and Surfaces A: Physicochemical and Engineering Aspects, vol. 312, no. 2-3, pp. 160-165, 2008.

[13] H. Al-Johani and M. A. Salam, "Kinetics and thermodynamic study of aniline adsorption by multi-walled carbon nanotubes from aqueous solution," Journal of Colloid and Interface Science, vol. 360 , no. 2 , pp. 760-767, 2011.

[14] B. Bina, H. Pourzamani, A. Rashidi, and M. Mehdi Amin, "Ethylbenzene removal by carbon nanotubes from aqueous solution," Journal of Environmental and Public Health, vol. 2012, Article ID 817187, 8 pages, 2012.

[15] A. H. Hamza, A. A. Muataz, and L. Tahar, "Removel of phenol by carbon nanotubes and activated carbon-a comparative analysis," in Proceedings of the 16th International Water Technology Conference, vol. 16, pp. 1-7, 2012.

[16] I. M. Mohamed, N. J. Saleh, and L. H. Mohmood, "Development a method for production of carbon nanotubes," Journal of Engineering, vol. 18, no. 8, pp. 905-913, 2012.

[17] G. E. J. Poinern, D. Parsonage, T. B. Issa, M. K. Ghosh, E. Paling, and Singh, "Preparation, characterization and $\mathrm{As}(\mathrm{V})$ adsorption behaviour of CNT-ferrihydrite composites," International Journal of Engineering, Science and Technology, vol. 2, no. 8, pp. 1324, 2010.

[18] A. Cao, C. Xu, J. Liang, D. Wu, and B. Wei, "X-ray diffraction characterization on the alignment degree of carbon nanotubes," Chemical Physics Letters, vol. 344, no. 1-2, pp. 13-17, 2001.

[19] M. Philippe, Growth mechanism and structure of carbon nanotubes [Ph.D. thesis], University of Fribourg, Fribourg, Switzerland, 2003.

[20] C. Lu, F. Su, and S. Hu, "Surface modification of carbon nanotubes for enhancing BTEX adsorption from aqueous solutions," Applied Surface Science, vol. 254, no. 21, pp. 7035-7041, 2008.

[21] T. A. Pham, S. M. Son, and Y. T. Jeong, "Water-dispersible multiwalled carbon nanotubes and novel hybrid nanostructures," Synthesis and Reactivity in Inorganic, Metal-Organic and NanoMetal Chemistry, vol. 40, no. 4, pp. 216-224, 2010.

[22] F. A. Abuilaiwi, T. Laoui, M. Al-Harthi, and M. A. Atieh, "Modification and functionalization of multiwalled carbon nanotube (MWCNT) via fischer esterification," Arabian Journal for Science and Engineering, vol. 35, no. 1, pp. 37-48, 2010.

[23] N. M. Vesali, A. A. Khodadadi, Y. Mortazavi, S. O. Alizadeh, F. Pourfayaz, and S. S. Mosadegh, "Functionalization of carbon nanotubes using nitric acid oxidation and DBD plasma," International Journal of Chemical and Biological Engineering, vol. 2, no. 2, pp. 66-68, 2009.

[24] S. Daniela, Z. Carmen, and R. Gabriela, "Reactive dye removal from aqueous solution by sorption on modified ash," Cercetari Agronomice in Moldova, vol. 43, no. 141, pp. 59-65, 2010.

[25] K. Yang and B. Xing, "Desorption of polycyclic aromatic hydrocarbons from carbon nanomaterials in water," Environmental Pollution, vol. 145, no. 2, pp. 529-537, 2007. 
[26] K. Shrivas and H.-F. Wu, "Functionalized-multiwalled carbon nanotubes as a preconcentrating probe for rapid monitoring of cationic dyestuffs in environmental water using APMALDI/MS," Journal of Separation Science, vol. 31, no. 20, pp. 3603-3611, 2008.

[27] R. K. Rajoriya, B. Prasad, I. M. Mishra, and K. L. Wasewar, "Adsorption of benzaldehyde on granular activated carbon: kinetics, equilibrium, and thermodynamic," Chemical and Biochemical Engineering Quarterly, vol. 21, no. 3, pp. 219-226, 2007.

[28] S. Y. Wong, Y. P. Tan, A. H. Abdullah, and S. T. Ong, "Removal of basic blue 3 and reactive orange 16 by adsorption onto quartenized sugar cane bagasse," The Malaysian Journal of Analytical Sciences, vol. 13, no. 2, pp. 185-193, 2009.

[29] A. El-Maghraby and H. E. El Deeb, "Removal of a basic dye from aqueous solution by adsorption using rice hulls," Global Nest Journal, vol. 13, no. 1, pp. 90-98, 2011.

[30] M. R. Samarghandi, M. Zarrabi, M. N. Sepehr, A. Amrane, G. H. Safari, and S. Bashiri, "Application of acidic treated pumice as an adsorbent for the removal of azo dye from aqueous solutions: kinetic, equilibrium and thermodynamic studies," Journal of Environmental Health Science and Engineering, vol. 9, no. 1, pp. 33-44, 2012. 

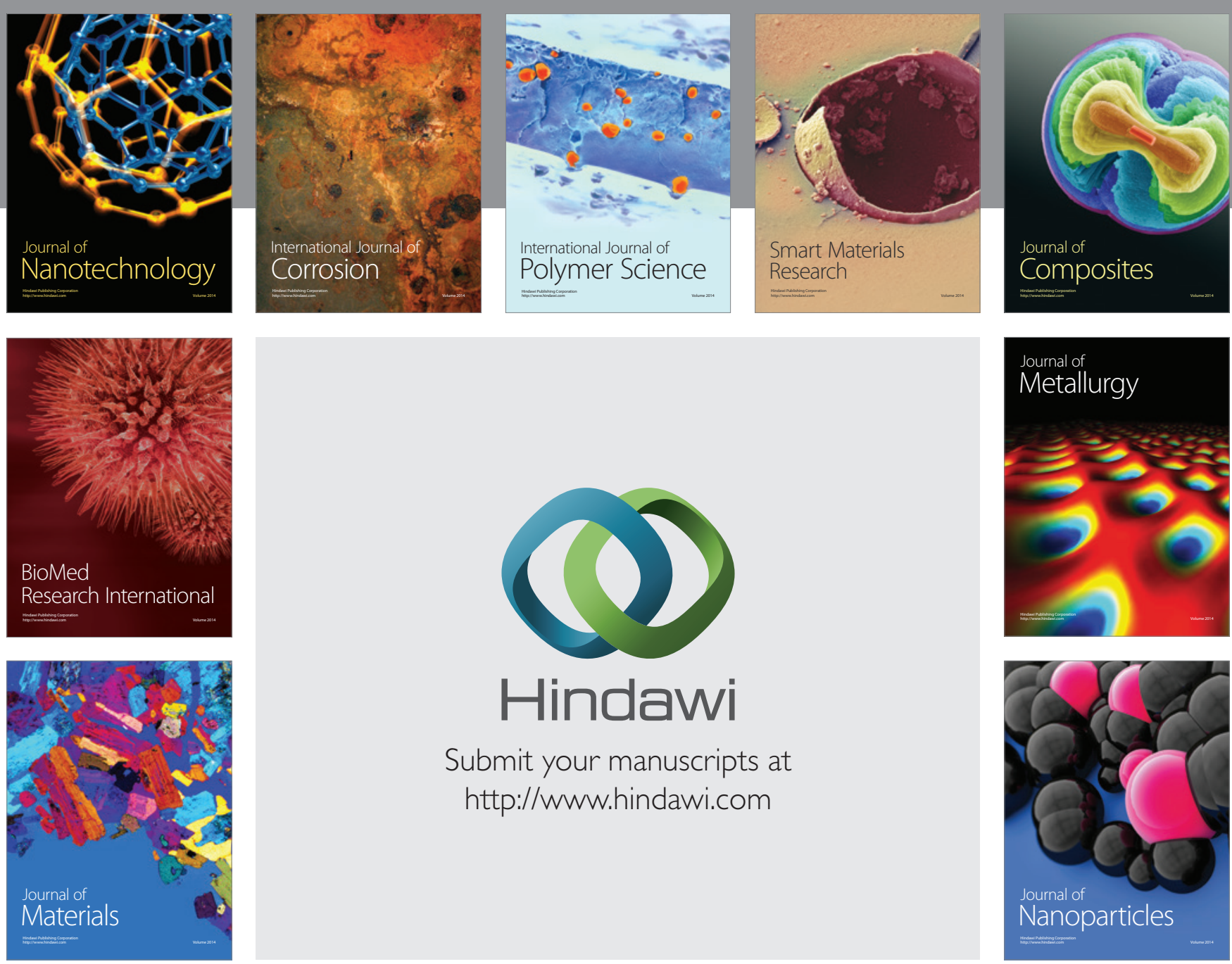

Submit your manuscripts at http://www.hindawi.com
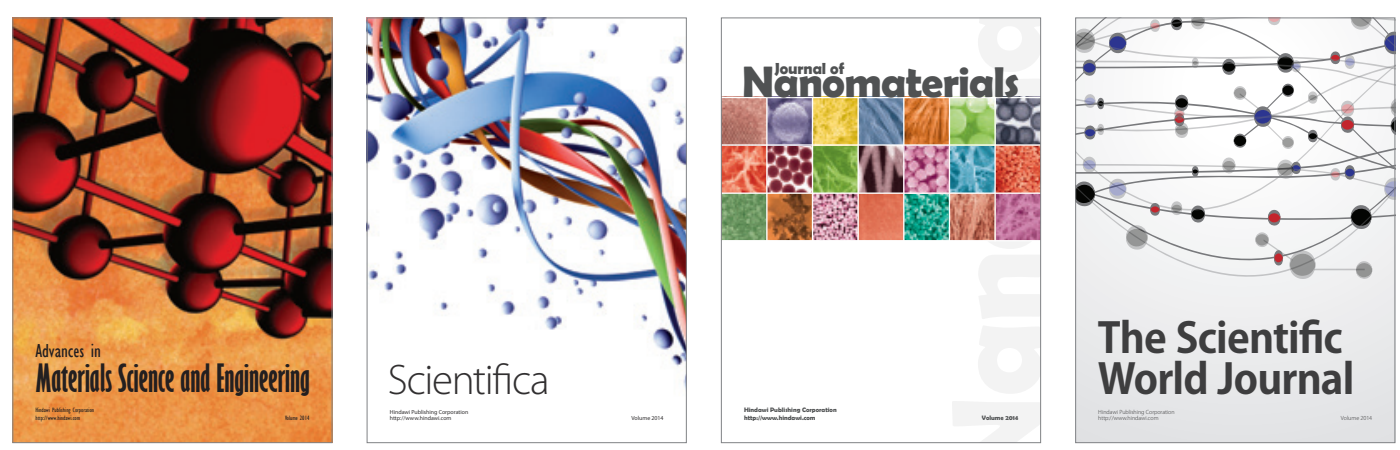

\section{The Scientific World Journal}
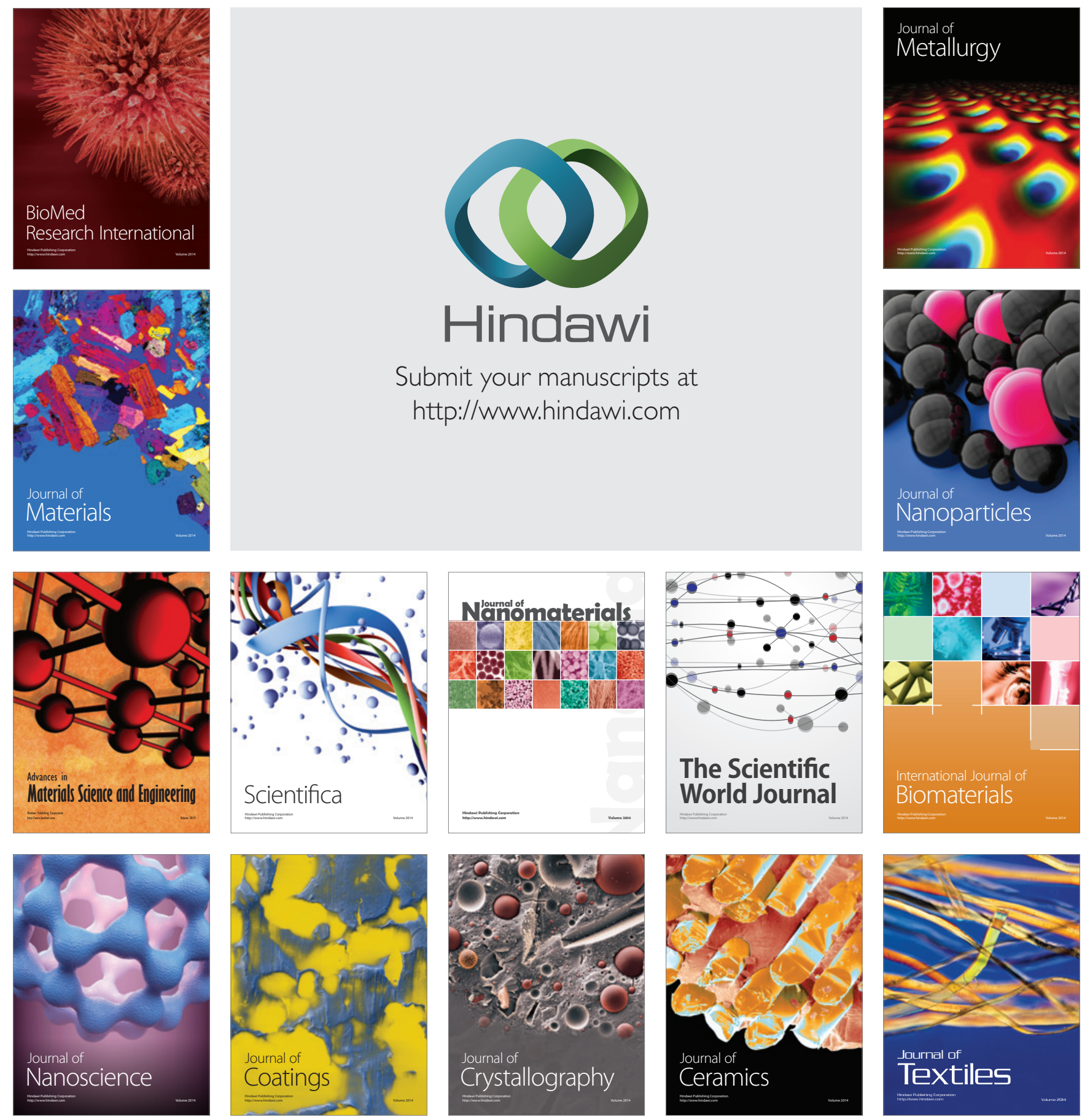